\title{
Transactivation of Core Binding Factor $\alpha 1$ as a Basic Mechanism to Trigger Parathyroid Hormone-Induced Osteogenesis
}

\author{
Takashi Fujita, Ryo Fukuyama, Nobuo Izumo, Takao Hirai, Toru Meguro, \\ Hiromichi Nakamuta and Masao Koida* \\ Department of Pharmacology, Faculty of Pharmaceutical Sciences, Setsunan University, \\ Nagaotohgecho 45-1, Hirakata, Osaka 573-0101, Japan \\ Received October 26, 2000 Accepted May 15, 2001
}

\begin{abstract}
During 28-day culture of bone marrow- and calvaria-derived osteoblasts, the constant presence of parathyroid hormone (PTH)(1 - 34) retarded differentiation and nodule formation (NF) in a dosedependent fashion (C-phase). In contrast, addition of $\operatorname{PTH}(1-34)$ in late stage cultures (from day 10 to 21) accelerated NF (A-phase). The stable production of such an A-phase allowed us to study the mechanism of bone anabolic action of PTH(1 - 34). Subcellular localization studies of core binding factor $\alpha 1$ (Cbfa1) and reporter assays provided the results indicating that in the A-phase, $\mathrm{PTH}(1-34)$ triggers its bone anabolic action via enhancement of Cbfal transactivation. RT-PCR and Northern blot analyses revealed that alkaline phosphatase, osteocalcin and bone sialoprotein expression decreased in the C-phase and increased in the Aphase; however, expression of other bone proteins (Cbfa1, PTH/PTH-related peptide-receptor, osteopontin, collagen I $\alpha$, collagen I $\alpha 2$, vitamin K-dependent $\gamma$-glutamyl carboxylase) did not change in a phase transitionrelated manner. Ovariectomized osteopenic mice, treated with $\mathrm{PTH}(1-34)(4$ and $40 \mu \mathrm{g} / \mathrm{kg}$, s.c., every other day, 4 or 6 weeks), recovered lost bone, displayed elevated nuclear localization of Cbfa1 in tibiae without alteration of its cytosolic level and exhibited upregulation of expressions of the same set of proteins (alkaline phosphatase, osteocalcin and bone sialoprotein) in femora. These results obtained by a concerted study in vitro and in vivo suggest that PTH triggers its osteogenic action via promotion of the transactivation of Cbfa1.
\end{abstract}

Keywords: Parathyroid hormone, Osteogenesis, Osteoblast, Core binding factor $\alpha 1$, Transactivation

Parathyroid hormone (PTH) is a master hormone involved in calcium homeostasis $(1,2)$ and bone metabolism by acting on PTH/PTHrP (PTH-related peptide) receptor $(3-6)$. PTH may exert bone catabolic or anabolic action depending on its dosing modality $(7,8)$. Laboratory and clinical evidence have implicated PTH and its congeners as potential candidates for restoring lost bone in osteoporosis $(9-11)$. However, the basic mechanism underlying the bone anabolic action is poorly understood, possibly due to the difficulties associated with the consistent reproduction of the action in vitro $(12-16)$. Recently, Schiller et al. (17) appear to have succeeded in the development of an in vitro system, using MC3T3-E1 cells, in which PTH(1 - 34) was able to consistently produce bone anabolic action.

Core binding factor $\alpha 1$ (Cbfa1) also known as Runx2 has been identified as a transcription factor critical in the

*Corresponding author. FAX: +81-72-866-3108

E-mail: koida@pharm.setsunan.ac.jp maturation of osteoblasts and in intramembraneous and endochondral ossification (18). Cbfa1-gene-disrupted mice gave rise to boneless neonates, completely lacking mature osteoblasts. Moreover, bone-specific proteins (osteocalcin: OCN, bone silaloprotein: BSP, alkaline phosphatase: ALP) were absent or occured in low levels in these gene-disrupted animals. Given the relationship of Cbfal with the promoter genes specific for those proteins, in conjunction with the previously noted findings (19), it is now generally accepted that physiologic bone formation does not occur without nuclear signaling, which includes transactivation of the transcription factor. Furthermore, it may be expected that stimulation of transactivation would be involved in the mechanism of osteogenic therapeutics. The bone anabolic effect of PTH can not be an exception.

In the initial phase of the current study, an in vitro cell culture system was established that could consistently and separately develop bone catabolic and anabolic phases of $\mathrm{PTH}(1-34)$ action as a function of treatment time and cell 
type. A variety of mineralizing cells were tested, including primary cultures of mouse calvaria- and bone marrowderived osteoblastic cells and the clonal cell lines MC3T3E1 (20, 21) and MC4 (22).

Secondly, the relationship of each phase of PTH(1 - 34) action to Cbfa1 transactivation was analyzed $(23-26)$. Gel retardation assay, immunocytochemical localization study of Cbfa1, and reporter assays employing cells transfected with OCN promoter-luciferase reporters were utilized. These techniques permitted the identification of transactivation as a basic mechanism responsible for triggering the anabolic phase of action.

Third, the relationship of transactivation to downstream cellular responses was examined. The following osteoblastic parameters were monitored: i) development of ALP activity and nodule formation (NF); ii) mRNA expression profiles of OCN, BSP, osteopontin (OPN), ALP and collagen Is, all of which are known to fall under the control of Cbfa1 $(18,19)$; and iii) expression profiles of Cbfa1, $\mathrm{PTH} / \mathrm{PTHrP}$ receptor, vitamin K-dependent $\gamma$-glutamyl carboxylase and Distal-less 5 (Dlx-5) (27) as candidate factors involved in regulation of osteoblastic bone formation.

Finally, ovariectomized osteopenic mice were employed in order to determine if the sequence of events in nuclear signaling and the subsequent cellular anabolic response identified in vitro would indeed occur during PTH-induced osteogenesis in vivo.

The present results obtained by a concerted study conducted in vitro and in vivo, taken together, strongly suggest that PTH triggers its bone anabolic phase of action through acceleration of Cbfa1 transactivation in osteogenic cells, as predicted (28) and has been observed for bisphosphonates (29).

\section{MATERIALS AND METHODS}

\section{Materials}

Human PTH(1 - 34) was a gift from Suntory Ltd. (Osaka). $\alpha$-minimum Eagle's medium ( $\alpha$-MEM), fetal calf serum (FCS), $\beta$-glycerophosphate, collagenase and trypsin were purchased from Gibco (Gaithersburg, MD, USA). Unless otherwise indicated, all other reagents were obtained from Wako Pure Chemical Co. (Osaka) or Nacarai Tesque Co., Ltd. (Kyoto).

\section{Cell cultures}

Primary cultures of calvaria-derived osteoblasts were prepared from calvaria bones of ddy newborn mice (1 - 2day-old) (18). Bones were resected and minced with scissors in ice-cold $\alpha$-MEM. Fragments were initially digested with $1 \mathrm{ml} /$ calvarium of an enzyme mixture $(0.1 \%$ collagenase and $2.5 \%$ trypsin in PBS) at $37^{\circ} \mathrm{C}$ for $10 \mathrm{~min}$.
Cells were then released by four sequential 10-min digestions. A pool of cells was collected from digestions $2-5$ by centrifugation at $250 \times g$ for $5 \mathrm{~min}$. The cells were suspended in medium A ( $\alpha$-MEM supplemented with $10 \%$ FCS, $100 \mathrm{U} / \mathrm{ml}$ penicillin $\mathrm{G}$ and $100 \mu \mathrm{g} / \mathrm{ml}$ streptomycin sulfate) for seeding. Primary cultures of mouse bone marrow-derived osteoblasts were also prepared from newborn mice. In brief, femora were excised and washed in PBS and the ends of the bones were removed. The marrow was flushed with $10 \mathrm{ml}$ of medium A (10 $\mathrm{ml}$ syringe, 19 gauge needle) and suspended in $\alpha$-MEM for seeding. Osteoblastic properties of primary cultures were characterized by the following parameters: NF and expression of osteoblastic proteins (ALP, OCN, BSP, Cbfa1, PTH/PTHrP receptor), as illustrated in Fig. 6. MC4 was the generous gift of Dr. Renny T. Franceschi (University of Michigan School of Medicine, MI, USA). Growth, selection and experimental use were conducted as per the kind instructions of Dr. Franceschi. MT3T3-E1 cells were purchased from RIKEN cell bank (Ibaragi) and cultured in $\alpha$-MEM supplemented with $10 \%$ FCS and antibiotics.

Cells were seeded on multi-well plates (48 wells for assays of NF and ALP activities, 6 wells for RNA and gel retardation assays; Iwaki, Tokyo) at a density of $1-1.5$ $\times 10^{4}$ cells $/ \mathrm{cm}^{2}$, followed by incubation in a humidified atmosphere $\left(\mathrm{CO}_{2}\right.$ incubator; Sanyo, Osaka) of $5 \% \mathrm{CO}_{2}$ in air at $37^{\circ} \mathrm{C}$ for $24 \mathrm{~h}$ prior to experimentation. Cells were subsequently washed once with the medium for each experiment. The medium consisted of medium A, dexamethasone (1.0 mM), $\beta$-glycerophosphate $(100 \mu \mathrm{M})$ and ascorbic acid (AA, $50 \mu \mathrm{g} / \mathrm{ml}$ ) for bone marrow-derived osteoblasts; $\beta$-glycerophosphate $(100 \mu \mathrm{M})$ and AA for calvarial osteoblasts; or AA alone or AA plus pH 7.4 phosphate buffer (3 $\mathrm{mM}$ as phosphate) for MC3T3-E1 and MC4. PTH(1 - 34) was added to the medium. The medium was renewed or exchanged every $48 \mathrm{~h}$.

\section{Measurements of protein content, ALP activity and NF}

Protein concentration was determined using a BCA protein assay kit (Pierce Chemicals, Rockford, IL, USA). Cells were sonicated in $0.1 \mathrm{M}$ Tris buffer ( $\mathrm{pH}$ 7.2) containing $0.1 \%$ Triton X-100. ALP activity was measured with $p$ nitrophenylphosphate as a substrate in $0.05 \mathrm{M}$ 2-amino-2methyl-1-propanol and $2 \mathrm{mM} \mathrm{MgCl}_{2}$ (pH 10.5). $p$-Nitrophenol release was estimated based on absorbance at $410 \mathrm{~nm}$. NF was monitored microscopically and quantified by measuring $\mathrm{Ca}$ content of the culture plate. Extracellular deposits were decalcified with $0.6 \mathrm{~N} \mathrm{HCl}$ for $24 \mathrm{~h}$. Subsequently, calcium content of the supernatant was determined colorimetrically by the $o$-cresolphthalein complexone method using Calcium C-test Wako (Wako Pure Chemical Co.). Estimation of phosphate content provided $\mathrm{Ca} / \mathrm{P}$ ratio of $1.6-1.7$. 
Preparation of cytosolic and nuclear extracts and gel retardation assays

Cytosolic and nuclear extracts were prepared and gel retardation assays conducted as described by Dignum et al. (30) with minor modifications. Cells were homogenized using a Dounce homogenizer (B-type pestle) in 4 vol buffer A containing $1.5 \mathrm{mM} \mathrm{MgCl}, 10 \mathrm{mM} \mathrm{KCl}, 1.0 \mathrm{mM}$ EDTA, $1 \mathrm{mM}$ EGTA, $1 \mathrm{mM}$ dithiothreitol and $1 \mu \mathrm{g} / \mathrm{ml}$ each of protease inhibitors (aprotinin, leupeptin, pepstatin $\mathrm{A}$ and $p$-amidinophenyl-methanesulfonyl fluoride). Tergitol NP-40 (Sigma), an anionic surfactant, was subsequently added to achieve a concentration of $0.6 \%$. After 5-min cooling with ice, homogenates were centrifuged at $20,000 \times g$ for $5 \mathrm{~min}$. Supernatants were mixed with stock solutions for buffer B (400 mM KCl, $1 \mathrm{mM}$ EDTA, $1 \mathrm{mM}$ EGTA, $10 \%$ glycerol and $1 \mu \mathrm{g} / \mathrm{ml}$ each of the above protease inhibitors in $50 \mathrm{mM}$ Tris- $\mathrm{HCl}$ buffer, $\mathrm{pH}$ 7.5) and stored at $-80^{\circ} \mathrm{C}$ as the cytosolic fractions. Pellets were resuspended in 4 vol buffer B, and after 30-min cooling with ice, suspensions were centrifuged at $20,000 \times g$ for $20 \mathrm{~min}$. Supernatants obtained were stored at $-80^{\circ} \mathrm{C}$ as the nuclear extracts. Protein concentrations were determined as described above. Double stranded oligonucleotides listed in the legend of Fig. 3 were individually labeled with $\left[\alpha-{ }^{32} \mathrm{P}\right]-$ dATP utilizing Klenow fragment. Purification was effected with a Nick column. Each DNA binding reaction mixture contained poly(d[I-C]) (Amersham-Pharmacia Biotech, Buchinghamshire, UK) and $3000-6000 \mathrm{cpm}$ of labeled DNA fragments in a buffer composed of $10 \mathrm{mM}$ Tris- $\mathrm{HCl}$ (pH 7.5), $50 \mathrm{mM} \mathrm{MgCl} 2,1 \mathrm{mM}$ DTT, $1 \mathrm{mM}$ EDTA, $1 \mathrm{mM}$ EGTA and $10 \%$ glycerol. Anti-mouse Cbfal antisera, the generous gift of Dr. Gerard Karsenty (Baylor College of Medicine, Houston, TX, USA), has been shown to specifically recognize Cbfal (19). In supershift assays, nuclear extracts were incubated with the antisera at $4^{\circ} \mathrm{C}$ for $30 \mathrm{~min}$ prior to the addition of labeled probe.

\section{Immunocytochemical localization of Cbfal}

Cells were fixed for $30 \mathrm{~min}$ in fresh $4 \%$ paraformaldehyde in PBS, rinsed with TBS-T, and then incubated with anti-Cbfa1 antibody (diluted 1:150) in 3\% BSA/TBS-T. Following a 1-h incubation at room temperature, cells were rinsed with TBS-T twice. Fluorescein isothiocyanateconjugated anti-rabbit Ig antibody (diluted 1:500) was subsequently introduced. The antibodies were washed away after a $1-\mathrm{h}$ incubation in the dark. Preparations were then rinsed, mounted in fluorescence mounting medium (Dako Pty Ltd., Carpinteria, CA, USA) and examined by an MRC-1024 confocal laser scanning microscope (BioRad Microscopy, Hemel Hempstead, UK). A preliminary test confirmed that binding of the antibody is not displaced by normal rabbit IgG.
DNA construction, transfection and luciferase assay

A set of pBluescript $\mathrm{KS}(-)$ containing the mOG2 promoter region (31), p6OSE2-luc and p6OSE2-mut-luc, was the gift of Dr. Gerard Karsenty. The pBluescript KS(-) was double-digested by Kpnl and HindIII. pBluescript was subcloned in the pGL3 promoterless luciferase expression vector (32). MC3T3-E1 cells were plated and cultured on $35-\mathrm{mm}$ dishes at a density of $10^{5} \mathrm{cell} / \mathrm{m}$. One day later, cells were transfected by FuGENE6 (Roche, Mannheim, Germany) according to the manufacturer's protocol, using $10 \mu \mathrm{g}$ of reporter plasmid constructs and $0.1 \mu \mathrm{g}$ of pRL-TK vector, utilized to normalize the transfection efficiency between different experiments. Stable transformants were prepared by double transfections employing the vector containing green fluorescent protein and neomycin resistance gene, pEGFP-N1 (Clontech Lab, Inc., Valencia, CA, USA) and luciferase vector. Subconfluent cells were trypsinized and plated at low density prior to selection. Cell selection was effected via culture in the presence of G418 $(400 \mu \mathrm{g} / \mathrm{ml})$ for 3 weeks; preculture was accomplished in AA-containing medium for 8 days. Cells were then incubated in AA plus phosphate $(3 \mathrm{mM})$ medium for $60 \mathrm{~h}$ and harvested by scraping into $0.5 \mathrm{ml}$ of Passive Lysis Buffer (Promega, Madison, WI, USA). Cells were subsequently lysed by three cycles of freezing-thawing. Luciferase activity was estimated with the Dual-Luciferase Reporter Assay System (Promega) and a model TD20/20 luminometer (Promega). The effect of $1 \mathrm{nM} \mathrm{PTH}(1-34)$ was observed to reach a plateau after a 48 -h incubation in a preliminary experiment. Consequently, $60 \mathrm{~h}$ was selected as the incubation period.

\section{Reverse transcription-polymerase chain reaction (RT- PCR)}

Total RNA was extracted by the guanidinium thiocyanate /phenol/chloroform method reported by Chomczynski and Sacchi (33). RT-PCR was performed as described (34) with several modifications. The oligonucleotides listed in Table 1 functioned as primers. All PCR products were subcloned into the EcoRV site of pBluescript $\mathrm{KS}+$ plasmid vector and sequenced completely to verify identity. Bands of interest were quantified with ImageQuant program (Molecular Dynamics, Sunnyvale, CA, USA). The data were corrected for background signal and plotted by Microsoft Excel software.

\section{Northern blot}

Northern blot was conducted under high stringency. In brief, $20 \mu \mathrm{g}$ total RNA were electrophoresed in $1.2 \%$ agarose-formaldehyde gel, transferred to a nylon membrane filter (Hybond $\mathrm{N}^{+}$, Amersham-Pharmacia Biotech) and hybridized with ${ }^{32} \mathrm{P}$-labeled cDNA probes. cDNAs encoding OCN, BSP and ALP cloned by PCR were utilized 
Table 1. List of PCR primers

\begin{tabular}{ll}
\hline Target mRNA & Primer sequences (5'-----------3')* \\
\hline Alkaline phosphatase (ALP) & GCA GGA TTG ACC ACG GAC ACT ATG \\
Bone sialoprotein (BSP) & TTC TGC TCA TGG ACG CCG TGA AGC \\
Collagen I $\alpha 1$ & CCG TTG TCT CCT CCG CTG CTG C \\
Collagen I $\alpha 2$ & CCT GGT AAA GAT GGT GCC \\
& CAC CAG GTT CAC CTT TCG CAC C \\
Core binding factor $\alpha 1$ (Cbfa1) & TGG TCC TCT GGG CAT CTC AGG C \\
& GGT GAA CCT GCT GTT GCC CTC A \\
Distal-less-5 (Dlx-5) & GCT GTT GTT GCT GTT GCT GT \\
Osteocalcin (OCN) & ACT ACG GCT ACC ACC CCT AC \\
Osteopontin (OPN) & AGT CCC AAA ACT GAG CAA GA \\
& GTT CAG GGT GTG TCG TCG AAC \\
PTH/PTHrP receptor & TTT CGG CTC GAC GGT CTC AAA \\
Vitamin K-dependent & CAT TGC CTC CTC CCT CCC GGT G \\
$\gamma$-gultamyl carboxylase & GTC ATC ACC TCG GCC GTT GGG G \\
& CCG TGA CCT TCT TCC TCT AC \\
& CAC AGT GTC CCT GAG ACC TC \\
& CTG GAC AAG ACA TCG TGG AA \\
& AGA GGT CAA GGA GAA GCC CA \\
& ATG GGT CAG AAG GAC TCC TAC \\
& ACG CTC GGT CAG GAT CTT CAT \\
\hline
\end{tabular}

*The upper is the sense primer and the lower is the antisense.

as probes. After the final washing, the membrane was exposed to a BAS imaging plate (Fuji Film, Tokyo) and relative signal intensity was estimated.

\section{Ovariectomy-induced osteopenia in mice and PTH treat- ment}

Sixty-six ddY female mice (12 weeks of age) were obtained from SLC (Shizuoka). Feeding is as described for rats (35). The animals were divided into 13 groups (typically 5 animals/group) based on receiving no operation, sham operation (SHAM) or ovariectomy (OVX) as follows: one group of controls received no operation and was analyzed 4 weeks later and 3 groups, each consisting of 4 subgroups (SHAM, OVX, OVX-Low and OVX-High). Beginning 4 weeks after surgery, ovariectomized mice were subcutaneously treated as follows: OVX, OVX-Low and OVX-High mice were treated with saline alone, $\mathrm{PTH}(1-34)$ $(4 \mu \mathrm{g} / \mathrm{kg})$ and $\mathrm{PTH}(1-34)(40 \mu \mathrm{g} / \mathrm{kg})$, respectively, every other day for 2, 4 or 6 weeks. Body weights were monitored for weekly adjustment of PTH dose. Two days after the final dosing, animals were analyzed.

\section{Dual-energy X-ray absorptiometry (DXA)}

Mineral contents of femora and tibiae were determined by DXA. Whole bones were placed on the platform of a DCS-600 (Aloka, Tokyo) and scanned with line spacing of
$0.508 \mathrm{~mm}$ and point resolution of $0.005 \mathrm{~mm}$. Bone mineral content and bone mineral density were calculated by using a regional high resolution analysis program for small animals.

\section{Data handling and statistics}

Data are presented as the mean \pm S.E.M. Unless otherwise indicated, statistical analysis performed using Student's $t$-test. Differences at $P<0.05$ were considered significant.

\section{RESULTS}

Sequential production of catabolic and anabolic phases of PTH action

ALP and NF activity in primary cultures of mouse bone marrow cells were detectable on culture day 5 and 7, respectively, as compared with day 3 , under the experimental conditions employed within the current investigation. Thereafter, ALP and NF activity continued to increase in a time-dependent manner up to 28 days (Fig. 1: A and B). Thereafter, ALP and NF activity continued to increase in a time-dependent manner up to 28 days (Fig. 1: A and B). The continuous presence of $\mathrm{PTH}(1-34)$ from culture day 0 decreased ALP and NF (Fig. 1: A and B) in a dosedependent manner (Fig. 1E for NF: C-phase). The mini- 
A

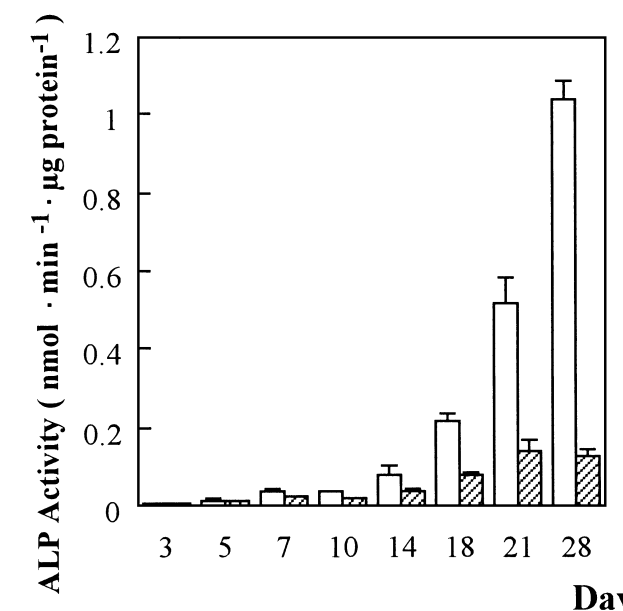

B

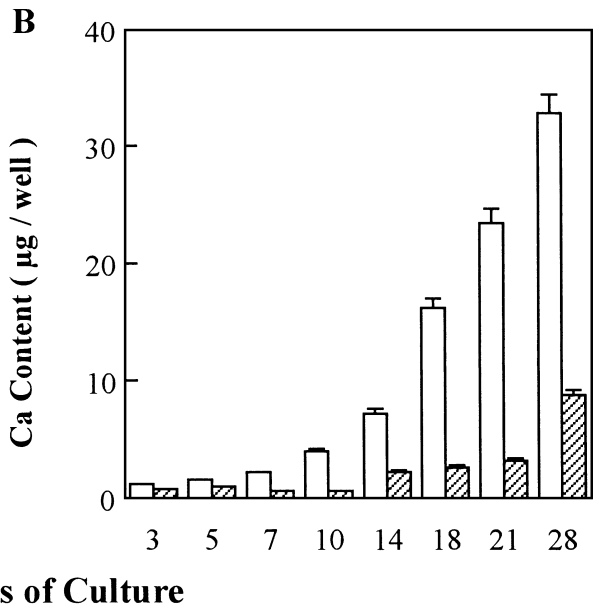

C
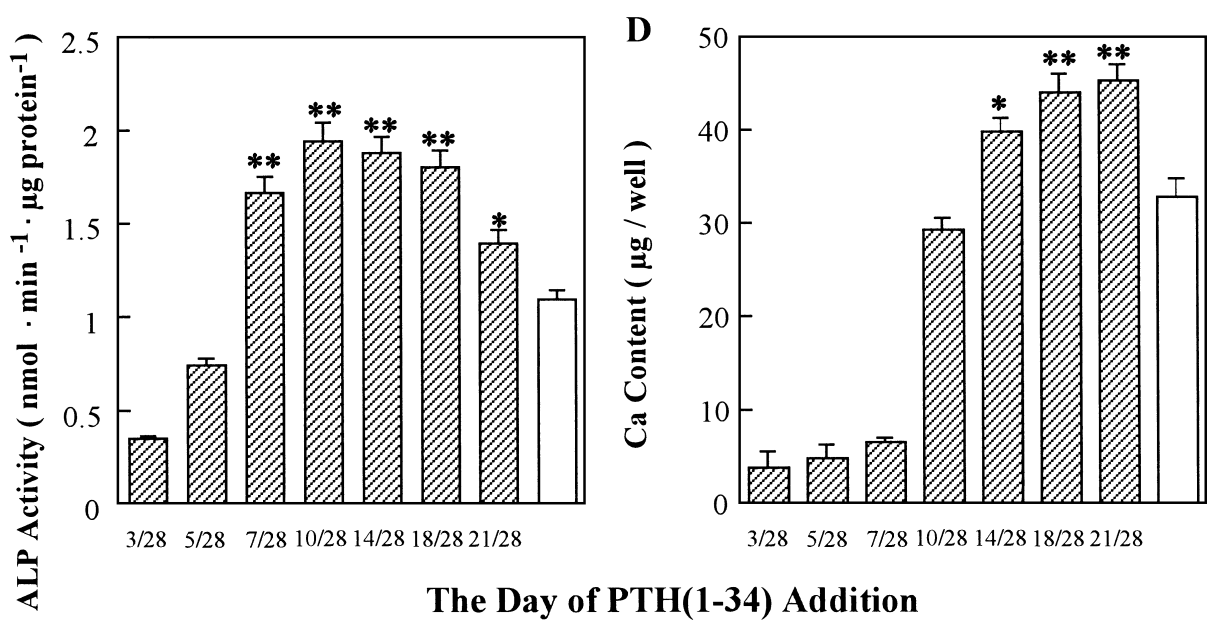

$\mathbf{E}$
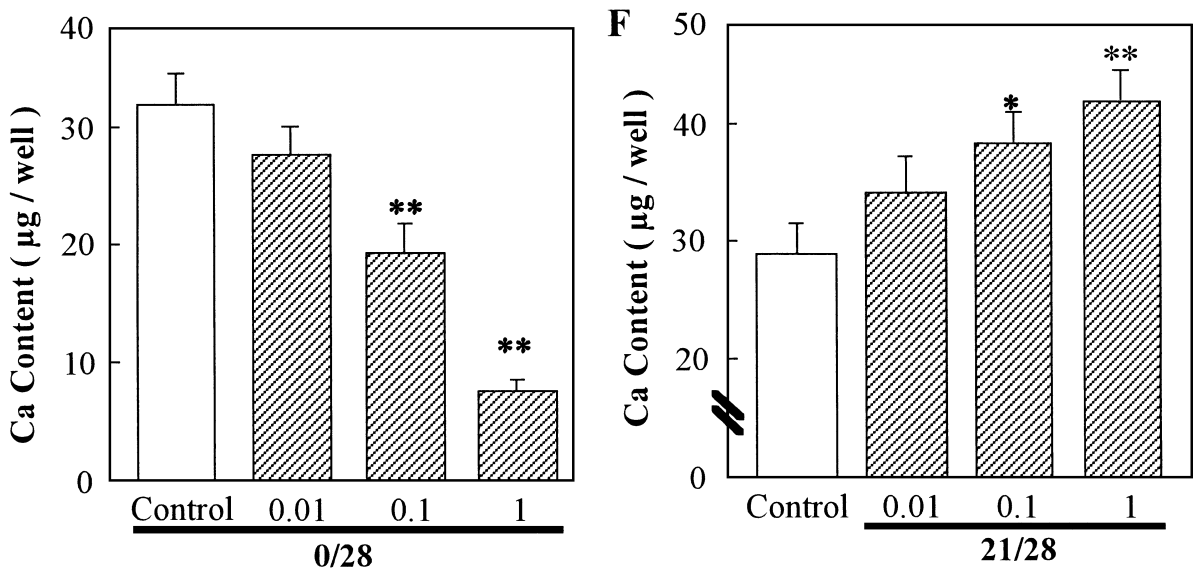

PTH(1-34) (nM)

Fig. 1. Biphasic action of PTH(1 - 34) on development patterns of ALP and NF activities during 28-day culture of mouse bone marrow-derived osteoblasts. In panels A and B, $1 \mathrm{nM} \mathrm{PTH}(1-34)$ was absent (open column) or present (striped column) from day 0 to the indicated day when both activities were measured. ALP activity began to significantly increase from day 5 and NF activity from day $7(P<0.05$ or less vs day 3$)$. In panels $\mathrm{C}$ and $\mathrm{D}, \mathrm{PTH}(1-34)$ was absent from day 0 to day 28 (open column) or present from the indicated day in the numerator to day 28 (striped column). In both cases, activities were measured on day 28. * and ** show significant differences from the open column at $P<0.05$ and $P<0.01$, respectively. Panels $\mathrm{E}$ and $\mathrm{F}$ show the dosedependency of the catabolic effect and anabolic effect of $\mathrm{PTH}(1-34)$, respectively. $\mathrm{PTH}(1-34)$ was absent (control) or present from day 0 (E) or day 21 (F) to day 28. * and ** show significant differences from each control at $P<0.05$ and $P<0.01$, respectively. Data are from 3 independent experiments $(n=8-16)$. 
mum effective concentration recorded was $0.1 \mathrm{nM}$ (Fig. 1E). When the presence of PTH $(1-34)$ was delayed by 14 days (hereafter referred to as 14/28) or longer, the peptide accelerated the development of both activities (Fig. 1: C and D: A-phase) in a dose-dependent manner (Fig. 1F). Similar results have been obtained for primary cultures of mouse calvarial cells (data not shown).

The anabolic phase of action observed with clonal cells is displayed in Fig. 2A. Delayed addition of PTH $(1-34)$ in a manner of $8 / 16$ accelerated NF activity by MC3T3-E1, but not by MC4 cells. In the latter clone, the C-phase of action ensued exclusively (Fig. 2B).

Gel retardation assay by Cbfal binding motifs in OCN promoter and effects of $P T H(1-34)$

Three Cbfa1 binding sites in OC promoter (OSE2, OSE1 and OCE1) were employed in order to analyze how the intracellular distribution pattern of Cbfa1 would change during the phase transition of $\mathrm{PTH}(1-34)$ action. In the absence of PTH(1 - 34), Cbfa1 measured by OSE2 binding tended to gradually decrease with culture time; moreover, this trend did not change in the C-phase (Fig. 3A). Similar results were obtained with OCE1 and OSE1 binding (data not shown). In the A-phase, PTH(1-34) invariably increased the nuclear level of Cbfa1. The cytosolic level remained unchanged. This effect seemed to be the maximum in a 14/28 manner of action (Fig. 3B).
A)

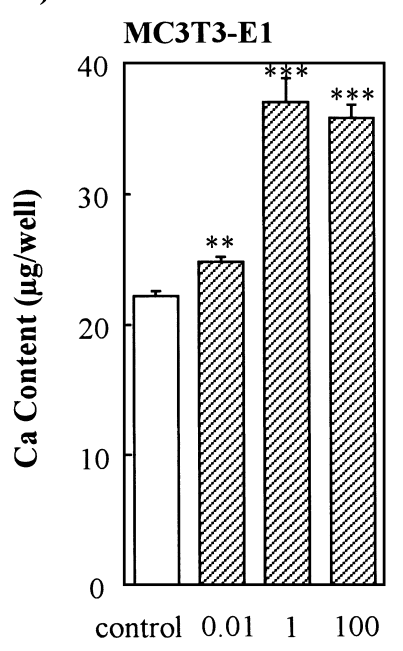

B)

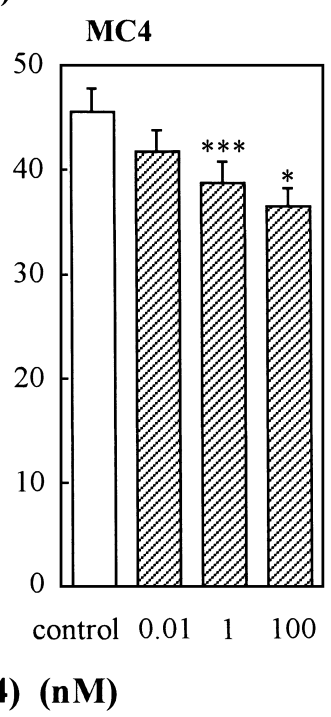

Fig. 2. Anabolic action of $\mathrm{PTH}(1-34)$ on NF of clonal cells. MC3T3-E1 (A) and MC4 (B) cells were cultured for 16 days followed by measurement of calcium deposition. PTH(1-34) was completely absent in the control (open column) or present solely for day 8 to day 16 (striped column) at the indicated concentrations. Data are from 3 independent experiments $(\mathrm{n}=8-16)$. *,** and $* * *$ show significant differences from each control at $P<0.05, P<0.01$ and $P<0.001$, respectively.
Immunocytochemical study of Cbfal transactivation and reporter assay

A series of immunocytochemical studies regarding Cbfa1 localization in MC3T3-E1 and calvarial primary culture cells demonstrated that, in the A-phase, PTH $(1-34)$ $(1 \mathrm{nM})$ rapidly translocated Cbfal into the nuclei which otherwise would be exported to the cytosol by $3 \mathrm{mM}$ phosphate (36). Figure 4 shows a typical result obtained with MC3T3-E1 cells. During preculture in AA plus medium, cells gradually accumulated Cbfa1 in the nuclei (data not shown); moreover, upon the addition of phosphate, cells exported accumulated nuclear Cbfa1. This process was typically completed within $30 \mathrm{~min}$, whereas $\mathrm{PTH}(1-34)$ appeared to promote further accumulation by hours. The time course of nuclear exit and entry of Cbfal in the experiment was followed by gel retardation assay (Fig. 4D). Findings (Fig. 4D) revealed that phosphate quickly exported nuclear Cbfa1; however, $\operatorname{PTH}(1-34)$ later not only reversed the effect of phosphate but rather promoted the concentration of Cbfa1 in the cell nuclei. As reported (36), phosphate acts on osteogenic cells as a signal to keep the nucleus Cbfa1-free. Although the data are not shown, similar results were obtained regarding the nuclear import of Cbfa1 in primary culture cells after 14-day culture and phosphate addition.

Reporter assays using MC3T3-E1 cells transfected with p1.3OG2-luc, p6OSE2-luc or p6SE2-mut-luc genes demonstrated that PTH $(1-34)$ accelerated OCN gene expression by activating the OCN gene, since this effect was not observed in the cells transfected with p6SE2-mut-luc (Fig. 5: A and B).

Culture time-dependent analysis of $m R N A$ revealed expression profiles of osteoblastic proteins and effects of PTH(1 34)

Experiments conducted in parallel with those described in Fig. 1 demonstrated measurable expression profiles of OCN, BSP and ALP mRNAs only after 12 days culture (Fig. 6A). NF practically began at that point and $\mathrm{PTH}(1-$ 34 ), present from day 0 , almost completely inhibited all the expressions (Fig. 6A). In contrast, mRNA expression of other proteins, including $\mathrm{Cbfa} 1, \mathrm{PTH} / \mathrm{PTHrP}$ receptor and OPN, was not noticeably affected by $\mathrm{PTH}(1-34)$ (some data in Fig. 6A and data relating to other proteins not shown).

Upon development of the A-phase in a 14/28 manner (Fig. 6B), the peptide was found to selectively upregulate the mRNA expressions of an exclusive set of proteins (OCN and BSP). Upregulation of ALP was monitored by the enzyme activity (Fig. 1C). Northern blot analysis of the A-phase confirmed the finding of PTH(1 - 34) upregulation of OCN expression (Fig. 6). 
A
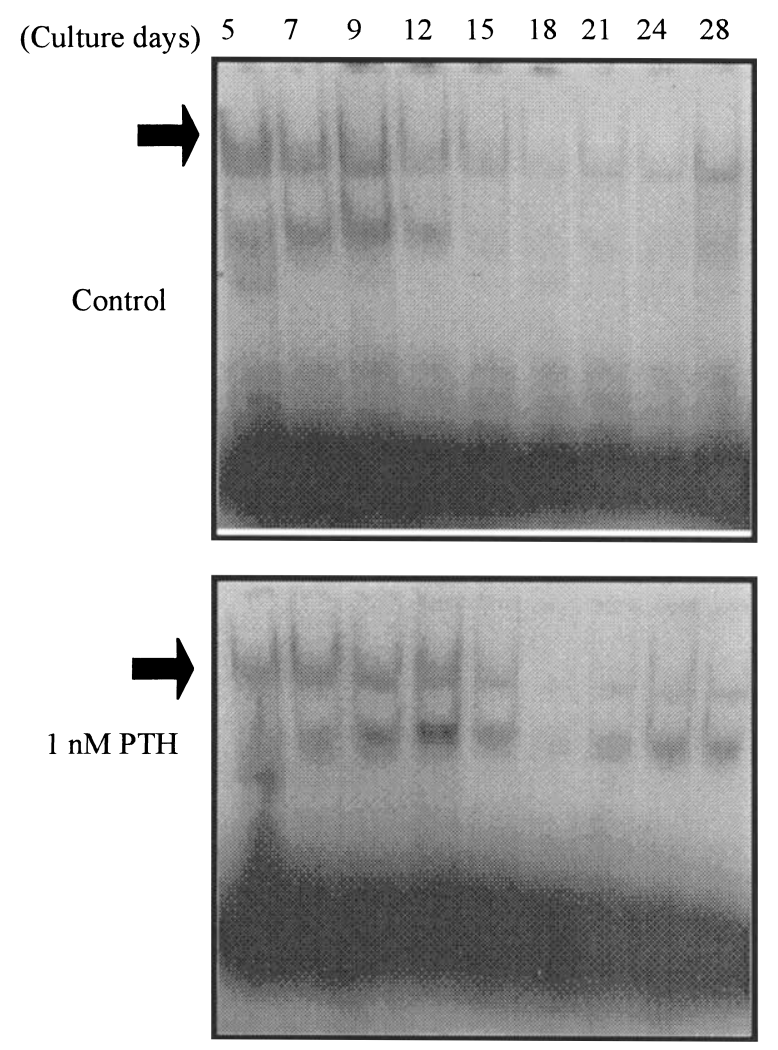

B
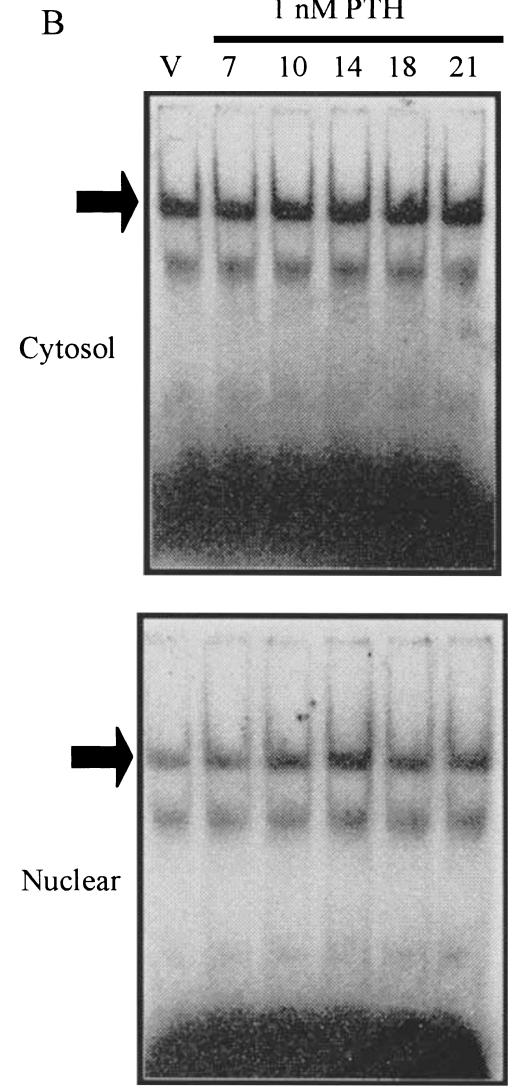

Fig. 3. Effect of PTH(1 - 34) on Cbfa1 binding to OSE2 in vitro. A: C-phase: Mouse bone marrow-derived cells were cultured from day 0 to the day indicated when binding was measured. In controls (upper panel), nuclear binding gradually decreased in a culture time-dependent manner; and as shown in the lower panel, in the presence of $\mathrm{PTH}(1-34)$, binding was suppressed initially but later appeared to form a delayed peak. B: A-phase: PTH(1 - 34) was present from the indicated day to day 28 when the cytosolic and nuclear extracts were separated. PTH(1 -34) did not affect the cytosolic level; however, it apparently upregulated nuclear translocation. $\mathrm{V}$ shows the vehicle-treated control measured on day $28(\mathrm{n}=4 /$ binding motif). Arrows indicate Cbfa1/OSE2 complex. Primers used included 5'-GAT CCA CTG AGC ACA TGA CCC CCA ATT AGT CCT A-3' (sense) and 5'-GAT CTA GGA CTA ATT GGG GGT CAT GTG CTC AGT G-3' (antisense) for OC-OCE1, 5'-GAT CCT CCC CTG CTC CTC CTG CTT ACA TCA GAG AGC ACA-3' (sense) and 5'-GAT CTG TGC TCT CTG ATG TAA GCA GGA GGA GCA GGG GAG-3' (antisense) for OCOSE1 and 5'-GAT CCG CTG CAA TCA CCA ACC ACA GCA-3' (sense) and 5'-GAT CTG CTG TGG TTG GTG ATT GCA GCG-3' (antisense) for OC-OSE2.

OVX-induced osteopenia-related changes in Cbfal transactivation and $m R N A$ expression profiles of selected bone proteins as well as the protective effect of PTH(1-34) treatment

As summarized in Table 2, OVX-mice developed osteopenia within 8 weeks after ovariectomy. PTH( 1 - 34) dosing for the last 4 or 6 weeks protected mice from osteopenia. Gel retardation assay of tibial extracts provided in vivo evidence indicating that $\mathrm{PTH}(1-34)$ dosing would enhance nuclear Cbfa1 binding (Fig. 7A). In addition, RT-PCR analysis of femoral extracts revealed that ovariectomy would suppress mRNA expressions of the same set of osteoblastic proteins, OCN, BSP and ALP. Moreover, PTH $(1-34)$ dosing would rescue the animals from OVXinduced suppression (Fig. 7B). Although the data are not shown, unchanged OPN and collagen Is expression have been observed under PTH(1 - 34) dosing.

\section{DISCUSSION}

\section{PTH action in C-phase}

As confirmed in the latter part of this study, the bone anabolic action of PTH is readily reproduced in vivo. In contrast, most attempts to produce this effect in vitro in the past have encountered uncontrollable difficulties caused by the catabolic phase of PTH action, which, without exception, preceded the anabolic action. The present investigation set out to first characterize the catabolic phase, which is readily reproduced by the constant presence of PTH from the beginning of culture. In the C-phase, PTH(1 - 34) retarded osteoblast differentiation and strongly suppressed development of ALP activity and NF; more- 

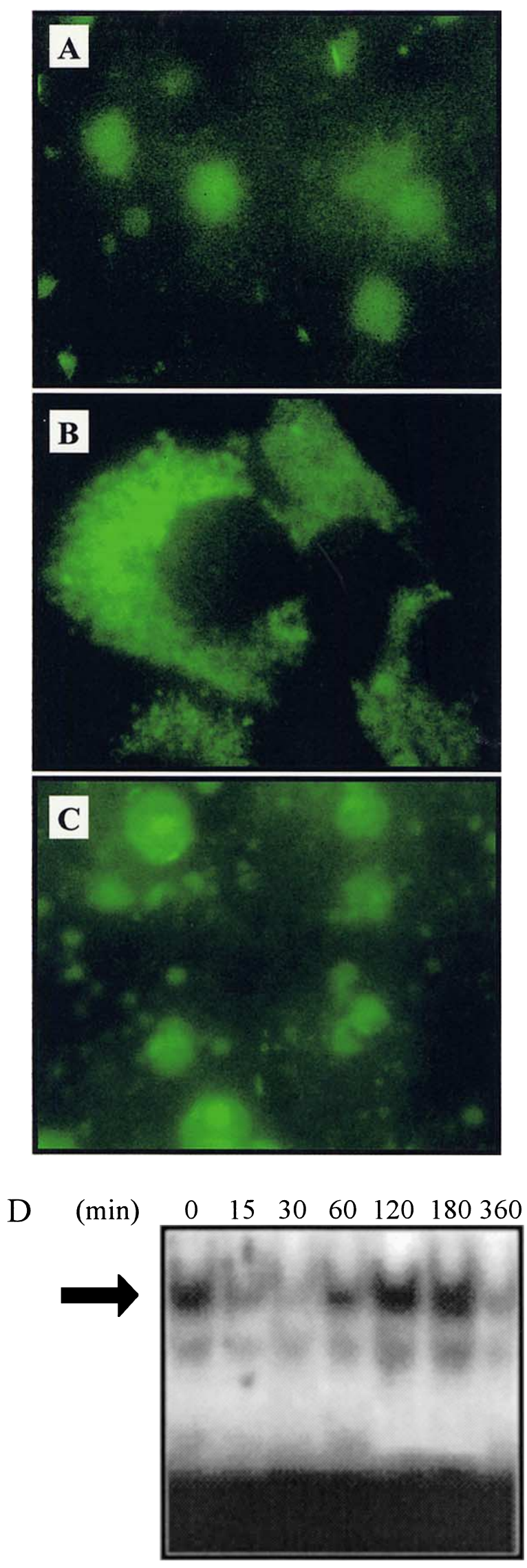
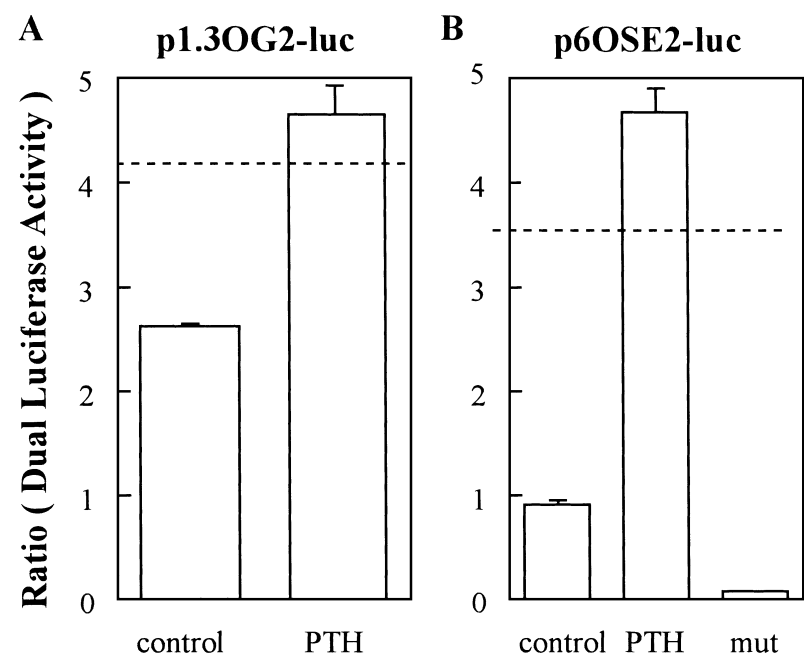

Fig. 5. PTH-induced increase of luciferase activity in extracts from MC3T3-E1 cells transfected with p1.3OG2-luc or p6OSE2-luc but not with p6OSE2-mut-luc. Following double transfection and 8-day preculture in AA plus medium, MC3T3-E1 cells were cultured in media containing AA plus $3 \mathrm{mM}$ phosphate without (control) or with $1 \mathrm{nM}$ PTH( $1-34)$ for $60 \mathrm{~h}$. Luciferase activity in cell lysates was subsequently measured. In a preliminary experiment, induction by $1 \mathrm{nM}$ PTH $(1-34)$ attained a maximum after a $48 \mathrm{~h}$-culture. PTH(1-34) promoted the expression of either p1.3OG2-luc or p6OSE2-luc but not of p6OSE2-mut-luc (mut). The horizontal dotted lines represent the averaged levels of luciferase activity at the end of preculture $(n=3)$.

over, expression of mRNAs of a set of osteoblast marker proteins (OCN, BSP and ALP) was blocked. In contrast, other proteins (OPN, Cbfa1, collagen Is, etc.) were continuously expressed and these expression levels were not affected by PTH $(1-34)$. These results appear to demonstrate that PTH $(1-34)$ specifically suppresses the expression of a set of genes that are essential for or accompanied by final differentiation to nodule-forming mature osteoblasts in the C-phase. Moreover, PTH(1 - 34) does not affect expression of extracellular matrix proteins, i.e., collagens, and their

Fig. 4. Immunocytochemical detection of PTH-induced transactivation of Cbfa1. After 8-day preculture, MC3T3-E1 cells were incubated in media containing AA alone (A), AA plus phosphate (B) and AA plus phosphate plus $1 \mathrm{nM}$ PTH(1-34) (C) for $90 \mathrm{~min}$ and processed for immunocytochemistry. Optimum incubation time was selected based on a preliminary experiment. A: Cbfal appeared to have been continuously synthesized and accumulated in the nuclei during preculture. B: Phosphate rapidly evacuated Cbfa1 from the nuclei. C: PTH $(1-34)$ appeared to continue the nuclear accumulation of Cbfa1. D: Cells were treated as in panel $\mathrm{C}$ and the time course of nuclear export and import of $\mathrm{Cbfa} 1$ was monitored by gel retardation assay. The arrow indicates Cbfa1/OSE2 complex. Phosphate, a nuclear export signal for Cbfa1 in osteogenic cells (refer to ref. 36), quickly drove Cbfal from the nucleus and thereafter kept the cell nuclei Cbfa1-free (data not shown), whereas PTH subsequently not only reversed the phosphate effect but later rather promoted the nuclear localization of Cbfa1 $(n=3)$. 
A

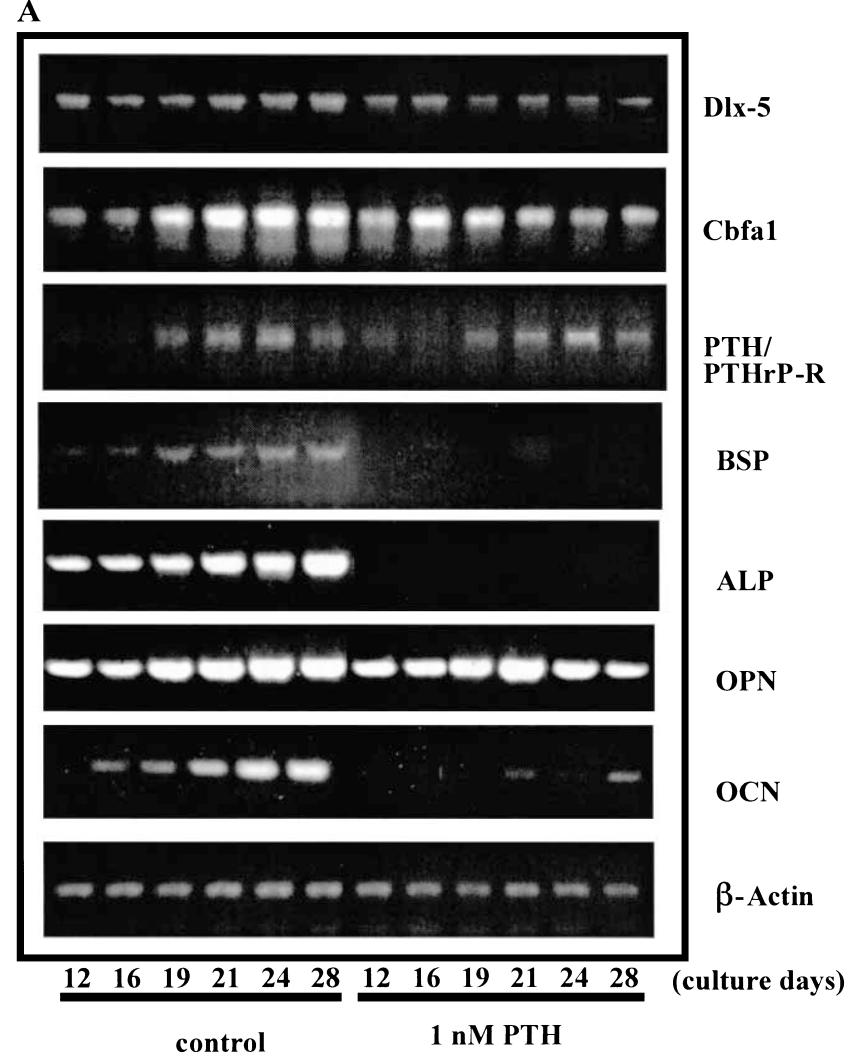

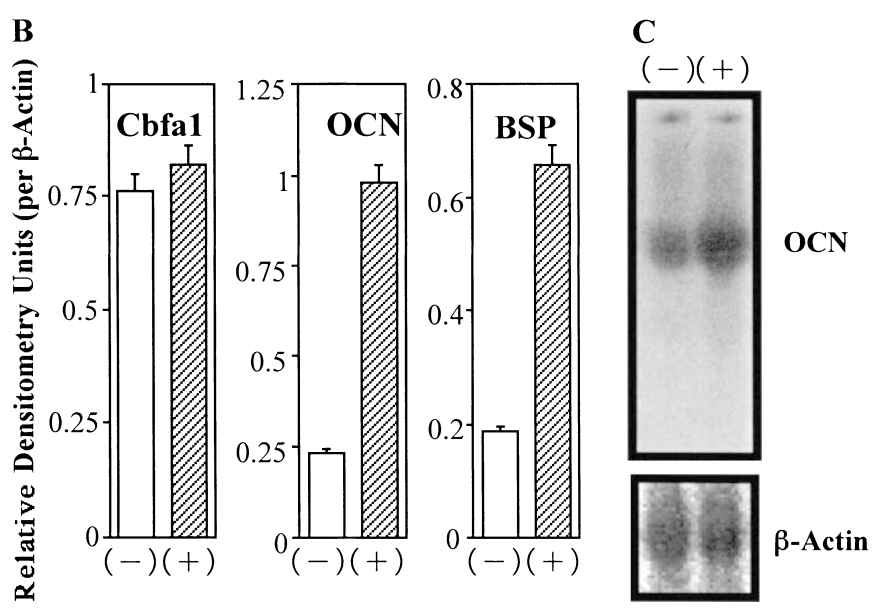

Fig. 6. Comparison of mRNA expression profiles of osteoblastic marker proteins in C- and A-phase of PTH $(1-34)$ action in carlvariaand bone marrow-derived osteoblasts. A: C-phase of action in calvaria-derived osteoblasts. The osteoblasts $\left(10^{7}\right.$ cells $/$ well $)$ were cultured in the absence (control) or presence of $1 \mathrm{nM} \mathrm{PTH}(1-34)$ to the indicated day (12 to 28 ); expression profiles of 8 proteins were subsequently analyzed by RT-PCR. B: A-phase of action in calvaria-derived osteoblasts. The osteoblasts $\left(10^{7}\right.$ cells/well $)$ were cultured for 28 days in the absence $(-)$ or presence $(+)$ of $1 \mathrm{nM}$ PTH(1 - 34) from day 14 to 28 ; RT-PCR analysis was subsequently performed on day 28 by densitometry $(n=4)$. C: A-phase action of PTH $(1-34)$ on the level of osteocalcin mRNA in bone marrowderived osteoblasts. The osteoblasts $\left(10^{7}\right.$ cells/well $)$ were cultured for 21 days in the absence $(-)$ or presence $(+)$ of $1 \mathrm{nM} \mathrm{PTH}(1-34)$ from day 14 to 21 ; Northern blot analysis was conducted on day 21 . The expression level was upregulated by $1 \mathrm{nM} \mathrm{PTH}(1-34)$ to $4.1 \pm 0.01$ fold $(n=6)$.

Table 2. Osteogenic effect of PTH(1 - 34) treatments on ovariectomized osteopenic mice

\begin{tabular}{|c|c|c|c|}
\hline \multirow[b]{3}{*}{ Treatment } & \multicolumn{3}{|c|}{ Duration (weeks) } \\
\hline & 2 & 4 & 6 \\
\hline & \multicolumn{3}{|c|}{ Femoral bone mineral content (mg) } \\
\hline Sham & $28.94 \pm 0.88$ & $29.14 \pm 0.71$ & $31.04 \pm 1.65$ \\
\hline ovX & $25.50 \pm 0.88$ & $25.48 \pm 0.82^{\star}$ & $26.92 \pm 1.33^{\pi}$ \\
\hline $\mathrm{OVX}+4 \mu \mathrm{g} / \mathrm{kg}$ PTH $(1-34)$ & $29.60 \pm 1.64$ & $29.72 \pm 1.42^{\dagger+, \#}$ & $28.94 \pm 0.90$ \\
\hline $\mathrm{OVX}+40 \mu \mathrm{g} / \mathrm{kg}$ PTH$(1-34)$ & $26.96 \pm 1.96$ & $29.88 \pm 0.88^{\dagger \dagger, \#}$ & $31.02 \pm 0.90^{\dagger, t}$ \\
\hline
\end{tabular}

Each value represents mean \pm S.E.M. ( $\mathrm{n}=5)$. ${ }^{\uparrow} P<0.05$ vs sham (Fisher's test); ${ }^{\dagger} P<0.05$ and ${ }^{\dagger \dagger} P<0.01$ vs OVX (Fisher's test), ${ }^{\sharp} P<0.05$ vs OVX (Dunnett's test).

modifying enzymes, i.e., vitamin K-dependent $\gamma$-glutamyl carboxylase.

The genes of ALP, OCN and BSP are known to possess Cbfa1 binding motifs in their promoter regions; furthermore, gene-targeting experiments have identified these genes as the major targets of $\mathrm{Cbfa} 1$ regulation $(18,19)$. It is possible that PTH(1 - 34)-induced change of the functional level of Cbfa1 triggers the C-phase. Throughout a monthlong culture period, the expression level of Cbfa1 was not significantly affected by the constant presence of $\mathrm{PTH}(1-$ 34). In addition, Cbfa1 nuclear binding appeared to gradually decrease in a NF-unrelated manner. These observations indicated that, in the absence of the osteogenic signal, neither cytosolic availability nor $\mathrm{Cbfa} 1$ transactivation would play a crucial role in NF. Continuous expression of the set of proteins (OCN, BSP and ALP) was observed under a constant $\mathrm{Cbfa}$ distribution pattern between the cytosol and the nuclei. This finding suggested that other transcrip- 
A

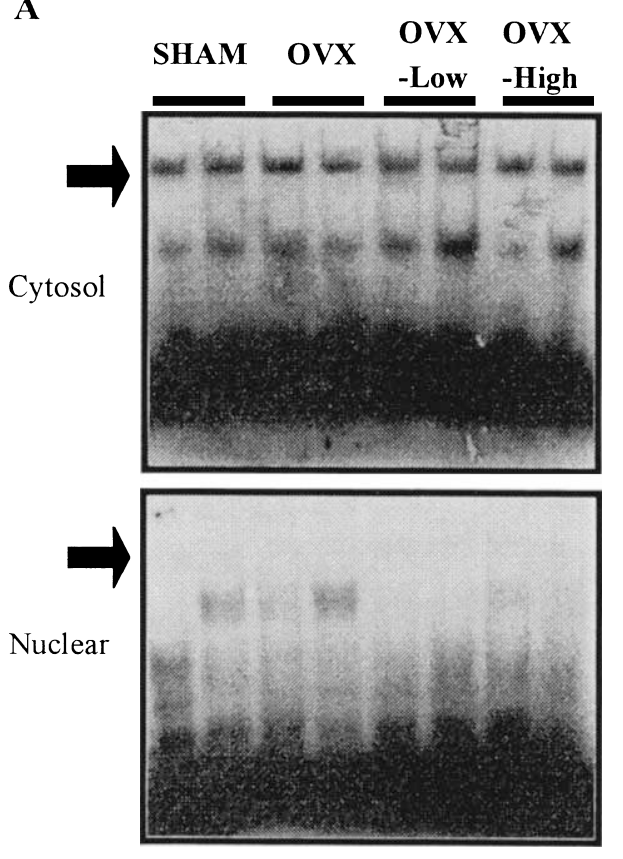

Fig. 7. Enhanced $\mathrm{Cbfa} 1$ binding to OSE 2 and enhanced expression of osteoblastic proteins in femora of mice, which recovered from OVX-induced osteopenia by 6 weeks of PTH $(1-34)$ treatment. Tibial samples were collected from all mice in Table 2. Data from the four 6-week-treated subgroups are in this figure: Sham: sham-operated, OVX: ovariectomized, OVX-Low OVX treated with $4 \mu \mathrm{g} / \mathrm{kg} \mathrm{PTH}(1-34)$, and OVX-High: OVX treated with $40 \mu \mathrm{g} / \mathrm{kg}$ PTH$(1-34)$. In panel A, nuclear Cbfa1 levels of tibial samples were lower than those of cultured cells in Fig. 3, A and B; however, the enhancing effect of PTH(1-34) dosing on binding was clearly detected. Panel B illustrates the enhancement of ovariectomy-suppressed expressions of a set of proteins to significantly higher levels than those in the sham group as a result of PTH(1 - 34) treatment. mRNA samples were amplified in duplicate by PCR $(\mathrm{n}=5)$. Arrows indicate Cbfa1/OSE2 complex. $* * *$ and $* * *$ show significant differences from the sham group at $P<0.05, P<0.01$ and $P<0.001$, respectively, and ${ }^{\dagger+\dagger}$ from the OVX group at $P<0.001$.

tion factor(s) or other types of factor(s) may be involved in nuclear signaling events to regulate expression of these proteins, as well as NF, in the absence of an osteogenic signal.

OCE1 binding oligonucleotides were used in the examination of the participation of other transcription factors. One target was b-helix-loop-helix-type transcription factors. These species are able to recognize the OCE1 motif; moreover, these factors have been suggested to play a variety of important roles in mesenchymal cell differentiation (37). Dlx-5 (27) was selected as it is known to bind to OCE1. Dlx-5 also functions in a Cbfa1-independent or cooperative fashion. However, expression of the Dlx-5 $\alpha$ subunit was not modified by PTH $(1-34)$ in a NF-related manner (Fig. 6A). Dlx-5 is among the genes identified to be
B

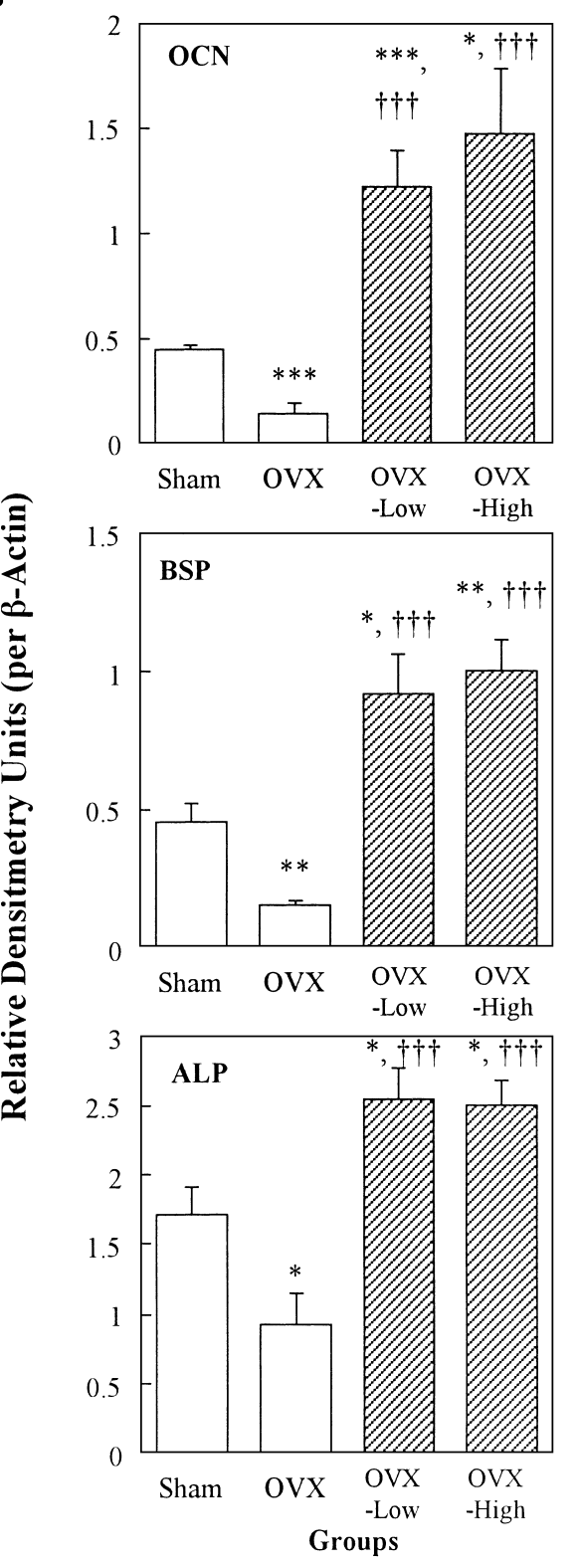

over-expressed during NF by differential display methodology. Consequently, primers were designed so as to detect all known variants of Dlx-5 (refer to Gene Bank for AN; $\alpha$ :AF022075, $\beta$ : AF022076 and $\gamma$ : AF022077). Neither isoform was amplified to detectable levels under our experimental conditions (data not shown).

\section{PTH action in A-phase}

Calvarial and bone marrow-derived osteoblastic cells were employed in the present study. Initial NF occurred on approximately the 7th day of culture; moreover, delayed addition of PTH(1 - 34) consistently induced the anabolic phase of action. Similar observations were made with respect to MC3T3-E1 cells. However, this cell type dis- 
played more rapid mineralization under our experimental conditions. Several groups have described the anabolic action of $\mathrm{PTH}(1-34)$ in vitro using cultured osteoblasts $(12-15)$. Gray and Jones (16) noted later, however, that the positive effect documented in earlier reports may have been due simply to the physicochemical shock of medium exchange. More recently, Schiller et al. (17) observed that the delayed presence of PTH $(1-34)$ in a $20 / 25$ fashion provided stable augmentation of NF by MC3T3-E1. The present investigation confirmed these results. Furthermore, we developed a shorter-term assay system using the same clone. Initiation of NF was accelerated by simply adding $2 \mathrm{mM}$ phosphate buffer to the culture medium.

Utilizing these in vitro assay systems so as to develop the A-phase, and by extending our study to in vivo experiments, we were first able to demonstrate that, either in vivo or in vitro, the bone anabolic action of PTH would be routinely initiated by nuclear signaling. Signaling included, at minimum, Cbfa1 transactivation. Consequently, this event then triggered a set of downstream cellular responses as seen in the enhanced expression of a specific set of osteoblastic marker proteins (Fig. 5). In other words, observations common to in vivo and in vitro experiments strongly suggest that PTH(1-34) exerts in vivo osteogenic effects by direct action on properly differentiated osteoblasts (e.g., as in a 14/21 culture in Fig. 1D). This action serves to trigger nuclear signaling via Cbfa1 transactivation, which then enhances or suppresses expression of selected sets of proteins (refer to OCN, ALP and BSP in Figs. 6 and 7) essential or associated with modification and mineralization of extracellular matrices, which appear to be constantly and sufficiently supplied (refer to collagens and vitamin Kdependent $\gamma$-glutamyl carboxylase in Fig. 6).

Of note is a particular finding from the experiment in Fig. 4. In AA plus medium, cells appear to continuously supply Cbfa1 to the cytosolic pool. Moreover, AA continues to slowly translocate Cbfa1 into the nucleus. Addition of $3 \mathrm{mM}$ phosphate, which had been used to accelerate initiation of NF, rapidly evacuated immunoreactive Cbfal from the nuclei, whereas $\mathrm{PTH}(1-34)$ completely reversed the phosphate effect. Although the data are not given, similar results have been obtained with primary cultures of calvarial osteoblasts. Thus far, completion of leptomycin Bsensitive nuclear export of Cbfal by phosphate in minutes relative to the hours exhibited by $\mathrm{PTH}(1-34)$ in nuclear import has been a consistent observation (36).

An additional question of interest pertains to the reason(s) PTH(1 - 34) failed to affect the expression levels of OPN and other osteoblastic proteins over the phase transition, despite the ability of Cbfa1 to function as a transcription factor for expression of this series of bone specific proteins. Porte et al. (38) have reported that both AP-1 and Cbfa1-like factor(s) are required for collagenase-inducing action of PTH. Involvement of other factor(s), functioning independently or cooperatively with $\mathrm{Cbfa} 1$, is highly possible in the expression of these PTH-unresponsive proteins.

In conclusion, a concerted laboratory effort including in vivo and in vitro experiments was conducted. The study allowed us to first identify accelerated Cbfal transactivation as a basic mechanism in the initiation of PTH-induced osteogenesis in vivo.

\section{REFERENCES}

1 Habener JF, Posenblatt M and Potts JT Jr: Parathyroid hormone: biochemical aspects of biosynthesis, secretion, action, and metabolism. Physiol Rev 64, 985 - 1053 (1984)

2 Mannstadt M, Jüppner H and Gardella TJ: Receptors for PTH and PTHrP: their biological importance and functional properties. Am J Physiol 277, F665 - F675 (1999)

3 Jüppner H, Abou-Samra AB, Freeman M, Kong XF, Schipani E, Richards J, Kolakowski LF Jr, Hock J, Potts JT Jr, Kronenberg HM and Segre GV: A G protein-linked receptor for parathyroid hormone and parathyroid hormone- related peptide. Science 254, 1024 - 1026 (1991)

4 Abou-Samra AB, Jüppner H, Force T, Freeman MW, Kong XF, Schipani E, Urena P, Richards J, Bonventre JV, Potts JT Jr, Kronenberg $\mathrm{HM}$ and Segre GV: Expression cloning of a common receptor for parathyroid hormone and parathyroid hormone-related peptide from rat osteoblast-like cells: a single receptor stimulates intracellular accumulation of both cAMP and inositol triphosphates and increases intracellular free calcium. Proc Natl Acad Sci USA 89, 2732 - 2736 (1992)

5 Bringhurst FR, Jüppner H, Guo J, Urena P, Potts JT Jr, Kronenberg HM, Abou-Samra AB and Segre GV: Cloned, stably expressed parathyroid hormone (PTH)/PTH-related peptide receptors activate multiple messenger signals and biological responses in LLC-PK 1 kidney cells. Endocrinology 132, 2090 2098 (1993)

6 Schipani E, Karga H, Karaplis AC, Potts JT Jr, Kronenberg HM, Segre GV, Abou-Samra AB and Jüppner H: Identical complementary deoxyribonucleic acids encode a human renal and bone parathyroid hormone $(\mathrm{PTH}) / \mathrm{PTH}$-related peptide receptor. Endocrinology 132, 2157 - 2165 (1993)

7 Tam, CS, Heersche JNM, Murray TM and Parsons JA: Parathyroid hormone stimulates the bone apposition rate independently of its resorptive action: differential effects of intermittent and continuous administration. Endocrinology 110, 506 - 512 (1992)

8 Podbesek R, Edouard C, Meunier PJ, Parsons JA, Reeve J, Stevenson RW, and Zanelli JM: Effects of two treatment regimes with syntheitc human parathyroid hormone fragment on bone formation and the tissue balance of trabecular bone in Greyhounds. Endocrinology 112, 1000 - 1006 (1983)

9 Morley P, Whitfield JF and Willick G: Anabolic effects of parathyroid hormone on bone. Trends Endocrinol Metab 8, $225-231$ (1997)

10 Morley P, Whitfield JF and Willick G: Parathyroid hormone analogues for treatment of osteoporosis and hypercalcemia. Exp Opin Ther Patents 8, 30 - 37 (1998)

11 Cosman $\mathrm{F}$ and Lindsay R: Is parathyroid hormone a therapeutic option for osteoporosis? A review of the clinical evidence. Calcif Tissue Int 62, 475 - 480 (1998) 
12 Isogai Y, Akatsu T, Ishizuya T, Yamaguchi A, Hori M, Takahashi N and Suda T: Parathyroid hormone regulates osteoblast differentiation positively or negatively depending on the differentiation stages. J Bone Miner Res 11, 1384 - 1393 (1996)

13 Ishizuya T, Yokose S, Hori M, Noda T, Suda T, Yoshiki S and Yamaguchi A: Parathyroid hormone exerts disparate effects on osteoblast differentiation depending on exposure time in rat osteoblastic cells. J Clin Invest 99, 2961 - 2970 (1997)

14 Hryhorenko L, Davies J and Sindrey D: Differentiation between anabolic and catabolic doses of PTH in the mineralization of primary bone marrow cell cultures on $\mathrm{CaP}$ slides. J Bone Miner Res 12, Suppl 1, S321 (1997)

15 Yang ZJ, Cheng V, Barnes S, Cavalho L and Sindrey D: Pulsatile parathyroid hormone (PTH) treatment increases bone formation in vitro in fetal rat calvarial cell (FRCC) culture system. J Bone Miner Res 12, Suppl 1, S317 (1997)

16 Gray C and Jones SJ: PTH(1 - 34) suppresses appositional bone formation by cultured rat cranial osteoblasts. Bone 23, $453-457$ (1998)

17 Schiller PC, D'ippolito G, Roos BA and Howard GA: Anabolic or catabolic responses of MC3T3-E1 osteoblastic cells to parathyroid hormone depend on time and duration of treatment. J Bone Miner Res 14, 1504 - 1512 (1999)

18 Komori T, Yagi H, Nomura S, Yamaguchi A, Sasaki K, Deguchi K, Shimizu Y, Bronson RT, Gao YH, Inada M, Sato M, Okamoto R, Kitamura Y, Yoshiki S, and Kishimoto T: Targeted disruption of Cbfa1 results in a complete lack of bone formation owing to maturational arrest of osteoblasts. Cell 89, $755-764$ (1997)

19 Ducy P, Zhang R, Geoffroy V, Ridall AL and Karsenty G: Osf2/Cbfa1: A transcriptional activator of osteoblast differentiation. Cell 89, 747 - 754 (1997)

20 Franceschi RT and Iyer BS: Relationship between collagen synthesis and expression of the osteoblast phenotype in MC3T3E1 cells. J Bone Miner Res 7, 235 - 246 (1992)

21 Quarles LD, Yohay DA, Lever LW, Caton R and Wenstrup RJ: Distinct proliferative and differentiated stages of murine MC3T3-E1 cells in culture: An in vitro model of osteoblast development. J Bone Miner Res 7, 683 - 692 (1993)

22 Wang D, Christensen K, Chawla K, Xiao G, Krebsbach PH and Franceschi RT: Isolation and characterization of MC3T3-E1 preosteoblast subclones with distinct in vitro and in vivo differentiation/mineralization potential. J Bone Miner Res 14, 893 903 (1999)

23 Frendo JL, Xiao G, Fuchs S, Franceschi RT, Karsenty G and Ducy P: Functional hierarchy between two OSE2 element in the control of osteocalcin gene expression in vivo. J Biol Chem 273, 30509 - 30516 (1998)

24 Thirunavukkarasu K, Mahajan M, McLarren KW, Stifani S and Karsenty G: Two domains unique to osteoblast-specific transcription factor Osf $2 / \mathrm{Cbfa} 1$ contribute to its transcription function and its inability to heterodimerize with $\operatorname{Cbf} \beta$. Mol Cell Biol 18, 4197 - 4208 (1998)

25 Harada H, Tagashira S, Fujiwara M, Ogawa S, Katsumata T, Yamaguchi A, Komori $\mathrm{T}$ and Nakatsuka M: Cbfa1 isoforms exert functional differences in osteoblast differentiation. J Biol Chem 274, 6972 - 6978 (1999)
26 Selvamurugan N, Pulumati MR, Tyson DR and Partridge NC: Parathyroid hormone regulation of the rat collagenase- 3 promoter by protein kinase A-dependent transactivation of core binding factor $\alpha 1$. J Biol Chem 275, 5037 - 5042 (2000)

27 Ryoo HM, Hoffman HM, Beumer T, Frenkel B, Towler DA, Stein GS, Stein JL, van Wijnen AJ and Lian JB: Stage-specific expression of Dlx-5 during osteoblast differentiation: involvement in regulation of osteocalcin gene expression. Mol Endocrinol 11, 1681 - 1694 (1997)

28 Fujita T, Fukuyama R, Izumo N, Meguro T, Nakamuta H and Koida M: Enhanced Cbfa1 transactivation as a basic mechanism to trigger bone anabolic action of PTH(1-34). J Bone Miner Res 15, Suppl 1, S373 (2000)

29 Fujita T, Izumo N, Fukuyama R, Meguro T, Yasutomi C, Nakamuta $\mathrm{H}$ and Koida $\mathrm{M}$ : Incadronate and etidronate accelerate phosphate-primed mineralization of MC4 cells via ERK1/2Runx2/Cbfa1 signaling pathway in a Ras-independent manner: further involvement of mevalonate-pathway blockade for incadronate. Jpn J Pharmacol 86, 86 - 96 (2001)

30 Dignam JP, Lebovitz RM and Roeder RG: Accurate transcription initiation by RNA polymerase II in a soluble extract from isolated mammalian nuclei. Nucl Acids Res 11, 1475-1489 (1983)

31 Ducy $P$ and Karsenty G: Two distinct osteoblast-specific cisacting elements control expression of a mouse osteocalcin gene. Mol Cell Biol 15, 1858 - 1869 (1995)

32 Yamamoto K, Hashimoto H, Hagihara N, Nishino A, Fujita T, Matsuda $\mathrm{T}$ and Baba A: Cloning and characterization of the mouse pituitary adenylate cyclase-activating polypeptide (PACAP) gene. Gene 211, 63 - 69 (1998)

33 Chomczynski $\mathrm{P}$ and Sacchi N: Single-step method of RNA isolation by acid guanidinium thiocyanate-phenol-chloroform extraction. Anal Biochem 162, 156 - 159 (1987)

34 Nogi H, Hashimoto H, Fujita T, Hagihara N, Matsuda T and Baba A: Pituitary adenylate cyclase-activating polypeptide (PACAP) receptor $\mathrm{mRNA}$ in the rat adrenal gland: localization by in situ hybridization and identification of splice variants. Jpn J Pharmacol 75, 203 - 207 (1997)

35 Fukushima T, Nitta T, Furuichi H, Izumo N, Fukuyama T, Nakamuta $\mathrm{H}$ and Koida M: Bone anabolic effects of PTH(1 34 ) and salmon calcitonin in ovariectomy- and ovariectomysteroid-induced osteopenic rats: a histomorphometric and biomechanical study. Jpn J Pharmacol 82, 240 - 246 (2000)

36 Fujita T, Izumo N, Fukuyama R, Meguro T, Nakamuta H, Kohno $\mathrm{T}$ and Koida $\mathrm{M}$ : Phosphate provides an extracellular signal that drives nuclear export of Runx/Cbfa1 in bone cells. Biochem Biophys Res Commun 280, 348 - 352 (2001)

37 Tamura $M$ and Noda $M$ : Identification of a DNA sequence involved in osteoblast-specific gene expression via interaction with helix-loop-helix (HLH)-type transcription factors. J Cell Biol 126, 773 - 782 (1994)

38 Porte D, Tuckermann J, Becker M, Baumann B, Teurich S, Higgins T, Owen MJ, Schorpp-Kistner M and Angel P: Both AP-1 and Cbfa1-like factors are required for the induction of interstitial collagenase by parathyroid hormone. Oncogene 18, $667-678$ (1999) 